\title{
Cardiac Innervation and Sudden Cardiac Death
}

\author{
Masaki Ieda and Keiichi Fukuda*
}

Department of Regenerative Medicine and Advanced Cardiac Therapeutics, Keio University School of Medicine, 35 Shinanomachi, Shinjuku-ku, Tokyo 160-8582, Japan

\begin{abstract}
The heart is extensively innervated and its performance is tightly controlled by the nervous system. Cardiac innervation density varies in diseased hearts leading to unbalanced neural activation and lethal arrhythmia. Diabetic sensory neuropathy causes silent myocardial ischemia, characterized by loss of pain perception during myocardial ischemia, which is a major cause of sudden cardiac death in diabetes mellitus (DM). Despite its clinical importance, the mechanisms underlying the control and regulation of cardiac innervation remain poorly understood.

We found that cardiac innervation is determined by the balance between neural chemoattractants and chemorepellents within the heart. Nerve growth factor (NGF), a potent chemoattractant, is induced by endothelin-1 upregulation during development and is highly expressed in cardiomyocytes. By comparison, Sema3a, a neural chemorepellent, is highly expressed in the subendocardium of early stage embryos, and is suppressed during development. The balance of expression between NGF and Seme3a leads to epicardial-to-endocardial transmural sympathetic innervation patterning. We also found that downregulation of cardiac NGF leads to diabetic neuropathy, and that NGF supplementation rescues silent myocardial ischemia in DM. Cardiac innervation patterning is disrupted in Sema3a-deficient and Sema3aoverexpressing mice, leading to sudden death or lethal arrhythmias. The present review focuses on the regulatory mechanisms underlying cardiac innervation and the critical role of these processes in cardiac performance.
\end{abstract}

Keywords: Cardiac nerve, nerve growth factor, Sema3a, arrhythmia, silent myocardial ischemia, sudden cardiac death.

\section{INTRODUCTION}

Cardiac innervation density is altered in diseased hearts, as in cases of congestive heart failure and myocardial infarction [1-3]. Following myocardial injury, cardiac nerves undergo denervation, which may be followed by Schwann cell proliferation and reinnervation, leading to heterogeneous patterns of innervation $[4,5]$. Abnormal sympathetic innervation may trigger lethal arrhythmia through ion channel modulation in cardiomyocytes [3, 6, 7]. In fact, there is circadian variation in the frequency of sudden cardiac death (SCD) that parallels sympathetic activity. $\beta$-blocker therapy prevents SCD secondary to ventricular tachyarrhythmia in ischemic heart disease or congestive heart failure [8, 9]. Immunohistochemical analysis of cardiac nerves in explanted hearts of transplant recipients reveals a positive correlation between nerve density and the clinical history of ventricular tachyarrhythmia [3]. Cardiac sensory denervation can also cause silent myocardial ischemia, characterized by loss of pain perception during myocardial ischemia and frequently leading to SCD in patients with diabetes mellitus (DM) [10]. Despite the severity of these complications, the molecular mechanism that determines innervation density in diseased hearts is poorly understood. Moreover, little is known about the anatomical distribution of cardiac nerves and the molecular mechanism regulating innervation during development [11]. The present review focuses on the

*Address correspondence to this author at the Department of Regenerative Medicine and Advanced Cardiac Therapeutics Keio University School of Medicine 35 Shinanomachi, Shinjuku-ku, Tokyo 160-8582, Japan;

Tel.; +81-3-5363-3874; Fax.; +81-3-5363-3875;

E-mail; kfukuda@sc.itc.keio.ac.jp regulatory mechanisms underlying cardiac innervation and the critical role of these processes in cardiac performance.

\section{ANATOMY OF CARDIAC NERVOUS SYSTEM}

The cardiac sympathetic nerves extend from the sympathetic neurons of stellate ganglia, which are located bilateral to the vertebra. Sympathetic nerve fibers project from the base of the heart into the myocardium, and are located predominantly in the subepicardium of the ventricle $[12,13]$. The central conduction system, which includes the sinoatrial node, atrioventricular node, and His bundle, is extensively innervated compared to the working myocardium [13-16]. We, and others, report that regional differences in cardiac sympathetic innervation, known as innervation patterning, are highly conserved among species [13, 14, 17].

The cardiac nervous system also involves afferent nerves. The sensory signals generated in the heart are conducted through cardiac afferent nerves, primarily thinly myelinated A $\delta$-fibers and nonmyelinated C-fibers [18, 19]. The sensory nerve fibers project to the upper thoracic dorsal horn via dorsal root ganglia neurons [18, 19]. Unlike sympathetic innervation, the anatomy of cardiac sensory innervation was poorly characterized until our recent report [20]. Cardiac sensory innervation will be discussed in more detail later in this review.

\section{NERVE GROWTH FACTOR UPREGULATION CAUSES NERVE SPROUTING AND SUDDEN CARDIAC DEATH}

Nerve growth factor (NGF) is a prototypic member of the neurotrophin family, the members of which are critical for 
the differentiation, survival, and synaptic activity of the peripheral sympathetic and sensory nervous systems [21-23]. The level of NGF expression within innervated tissues corresponds to innervation density [24].

Our recent investigations, and those of others, show that NGF expression is altered in diseased hearts [1-3, 25]. Studies in animal models by Zhou et al. [26] reveal that NGF is upregulated following myocardial infarction (MI), resulting in the regeneration of cardiac sympathetic nerves and heterogeneous innervation. In a previous study we report that NGF is upregulated in cardiac hypertrophy, leading to sympathetic hyperinnervation and rejuvenation [27]. NGF infusion after MI enhances myocardial nerve sprouting and results in a dramatic increase in SCD and a high incidence of ventricular tachyarrhythmia [1]. These results demonstrate that NGF-induced augmentation of sympathetic nerve sprouting in diseased hearts leads to lethal arrhythmia and SCD.

\section{NERVE GROWTH FACTOR DOWNREGULATION IS CRITICAL FOR DIABETIC NEUROPATHY AND SILENT MYOCARDIAL ISCHEMIA}

In contrast to sympathetic innervation, very little was known about sensory innervation and its alteration in diseased hearts. Visceral organs, including the heart, are believed to be rich in autonomic efferent innervation and poor in nociceptive afferent nerves [28]. Zahner et al. [29] report that vanilloid receptor-1-immunopositive sensory nerves are enriched in the epicardium and scarce in the myocardium. In immunohistochemical studies using anticalcitonin gene-related peptide antibody (CGRP), a sensory marker, we demonstrated, for the first time, that cardiac sensory innervation is rich at epicardial sites and in the ventricular myocardium [20, 30]. In a screen of several neurotrophic factors, we found that the development of cardiac sensory nerves parallels the production of NGF in the heart [31]. Cardiac nociceptive sensory nerves that are immunopositive for CGRP, including the dorsal root ganglia and the dorsal horn, are markedly retarded in NGF-deficient mice and rescued in mice overexpressing NGF specifically in the heart. Thus, NGF synthesis in the heart is critical for the development of the cardiac sensory nervous system [32].

The cardiac sensory nervous system is responsible for pain perception and in the initiation of the protective cardiovascular response during myocardial ischemia $[18,19$, $33,34]$. Cardiac sensory nerve impairment causes silent myocardial ischemia, a major cause of sudden death in DM patients [10]. Despite the severity of this complication, the alterations in cardiac sensory innervation and the molecular mechanism underlying sensory neuropathy in diabetic hearts is unclear [35-41]. To investigate whether NGF is involved in diabetic neuropathy, DM was induced with streptozotocin in wild-type (WT) mice and in transgenic mice that overexpressed NGF in the heart [20, 42-45]. Downregulation of NGF, CGRP-immunopositive cardiac sensory denervation, and atrophic changes in dorsal root ganglia were observed in DM-induced WT mice, whereas these deteriorations were rescued in DM-induced NGF-transgenic mice. Cardiac sensory function, measured by myocardial ischemiainduced c-Fos expression in dorsal root ganglia, was also downregulated by DM in the WT mice, but not in the NGFtransgenic mice [19]. Direct gene transfer of NGF into the diabetic rat hearts improved cardiac sensory inner-vation and function according to the electrophysiological activity of cardiac afferent nerves during myocardial ische-mia (Fig. 1) $[46,47]$. These findings demonstrate that DM-induced downregulation of NGF may lead to cardiac sensory neuropathy.
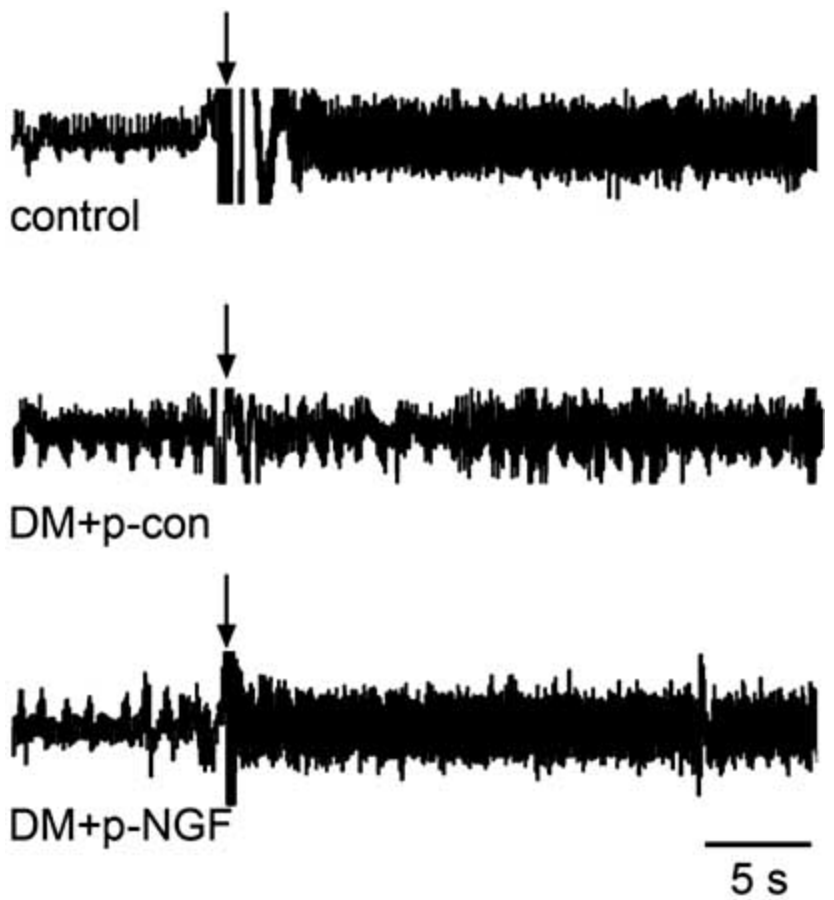

Fig. (1). NGF gene transfer restores impaired sensory innervation in diabetic hearts.

Recording of impulse activity from cardiac sympathetic afferent nerves. Myocardial ischemia was induced at the time point indicated by arrows. Note that the response of cardiac afferent nerves was reduced in DM injected with p-con (control). The gene transfer of $50 \mu \mathrm{g}$ p-NGF preserved cardiac sensory nerve function in DM.

Phase I and phase II clinical trials of systemic administration of recombinant NGF reveal the safety and potential efficacy of this treatment for diabetic polyneuropathy, although a phase III trial showed no beneficial effects, possibly because the dosage and route of administration was suboptimal $[48,49]$. It is possible that restriction of NGF dosage due to side-effects and the development of anti-NGF antibodies contributed to the lack of beneficial effects in the phase III clinical trial. To avoid these complications, gene transfer was used to directly administer the $N G F$ gene into the heart. Both NGF- and CGRP-immunopositive nerves were reduced in diabetic hearts, thereby demonstrating the successful treatment of cardiac sensory neuropathy by $N G F$ gene transfer. Consistent with our findings, the efficacy of $N G F$ gene therapy has been reported in diabetic cystopathy and neuropathy of the footpad $[49,50]$. Future studies on the reliability and efficacy of $N G F$ gene therapy are required before clinical trials can proceed. 


\section{ENDOTHELIN-1-INDUCED NGF UPREGULATION IS ESSENTIAL FOR CARDIAC SYMPATHETIC INNERVATION}

Although alteration in the level of NGF has a great impact on the clinical outcome in heart disease, the molecular mechanisms underlying the regulation of NGF expression and sympathetic innervation are poorly understood. To address this issue, we performed a screen of several cardiac hypertrophic factors and found that ET-1 specifically upregulates NGF expression in primary cultured cardiomyocytes [51]. Furthermore, we showed that ET-1-induced NGF augmentation was not observed in cardiac fibroblasts but was specific to cardiomyocytes, and identified signaling molecules involved in the ET-1/NGF pathway.

To study the effects of the ET-1/NGF pathway on the development of the cardiac sympathetic nervous system, we analyzed various gene-modified mouse models. NGF expression, cardiac sympathetic innervation, and norepinephrine concentration were reduced in ET-1-deficient mouse $\left(E d n 1^{-1-}\right)$ hearts, but not in the hearts of angiotensinogendeficient mice $\left(\mathrm{Atg}^{-/}\right)$. In $E d n 1^{-/-}$mice, the sympathetic stellate ganglia exhibited excessive apoptosis and displayed loss of neurons at the late embryonic stage [52]. Moreover, we demonstrated that cardiac-specific overexpression of NGF in $E d n 1^{-1-}$ mice overcomes sympathetic nerve retardation (Fig. 2) [53]. These findings indicate that ET-1 is a key regulator of NGF expression in cardiomyocytes, and that the ET-1/NGF pathway is critical for sympathetic innervation in the heart [54]. Given that ET-1 is strongly induced in myocardial infarction and cardiac hypertrophy, the ET1/NGF pathway may also be involved in NGF upregulation and nerve regeneration in pathological hearts.

\section{CARDIAC SYMPATHETIC INNERVATION PAT- TERNING IS DETERMINED BY SEMA3A EXPRES- SION}

The growth-cone behavior of nerves is determined by coincident signaling between neural chemoattractants and chemorepellents, synthesized in the innervated tissue. While
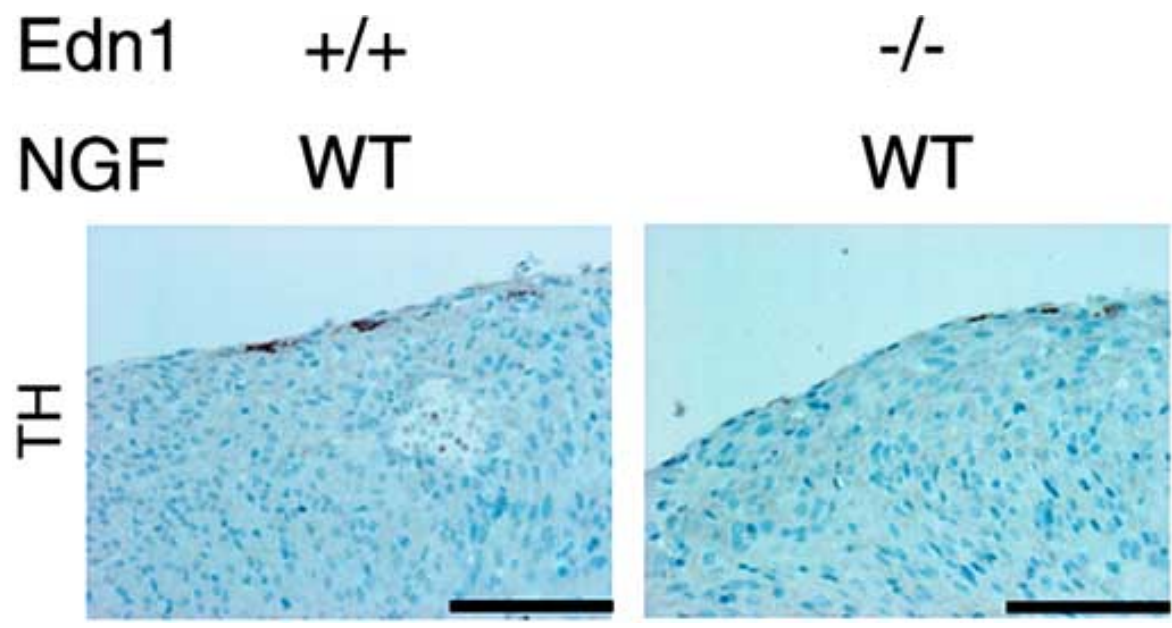

NGF plays critical roles in cardiac innervation as a chemoattractant, the neural chemorepellent that induces growthcone collapse and repels nerve axons is not found in the heart. Recently, we found that Sema3a inhibits neural growth and establishes appropriate innervation patterning in the heart [55].

Sema3a is a Class 3 secreted semaphorin and has been cloned and identified as a potent neural chemorepellent and a directional guidance molecule for nerve fibers [56-58]. For this reason, investigations were initiated to determine if cardiomyocytes produced Sema3a and if this protein played a role in sympathetic neural patterning and cardiac performance. We analyzed the kinetics and distribution of cardiac sympathetic innervation in developing mouse ventricles [55]. Sympathetic nerve endings, immunopositive for the sympathetic marker, tyrosine hydroxylase $(\mathrm{TH})$, appeared on the epicardial surface at embryonic day (E) 15 and then gradually increased in number in the myocardium after postnatal day (P)7 and P42. Sympathetic nerves were more abundant in the subepicardium than in the subendocardium of the ventricular myocardium, suggesting the presence of an epicardial-to-endocardial gradient that is consistent with previous reports $[12,14-16]$. We analyzed heterozygous Sema3a knocked-in lacZ mice $\left(\operatorname{Sema3} a^{\text {lacZ/+ }}\right.$ ) to investigate the expression pattern of Sema3a and its relationship to innervation patterning in the heart. At E12, strong lacZ expression was detected in the heart, especially in the trabecular components of the ventricles. By E15, lacZ expression was observed in the subendocardium, but not in the subepicardium, of the atria and ventricles. At $\mathrm{P} 1$ and $\mathrm{P} 42$, lacZ expression was reduced in certain regions and highlighted the Purkinje fiber network along the ventricular free wall [59, 60]. Quantitative RT-PCR of Sema3a in developing hearts revealed a linear decrease in the expression of Sema $3 a$ from E12 that corresponded with an increase in sympathetic innervation density. The negative correlation between the kinetics of Sema3a expression and sympathetic innervation indicates that Sema3a negatively regulates cardiac innervation in developing hearts (Fig. 3).

Fig. (2). Cardiac-specific overexpression of NGF overcomes the defects of cardiac sympathetic nervous system in Edn1 ${ }^{-/-}$mice. Immunostaining for TH in the hearts of Edn $1^{+/+}, \mathrm{Edn}^{-{ }^{--}}$and Edn $1^{-/} / \mathrm{MHC}-\mathrm{NGF}$ mice. The reduced sympathetic innervation in Edn $1^{-/-}$hearts is rescued in Edn $1^{-/} / \mathrm{MHC}-\mathrm{NGF}$ hearts. Scale bar, $100 \mu \mathrm{m}$. 

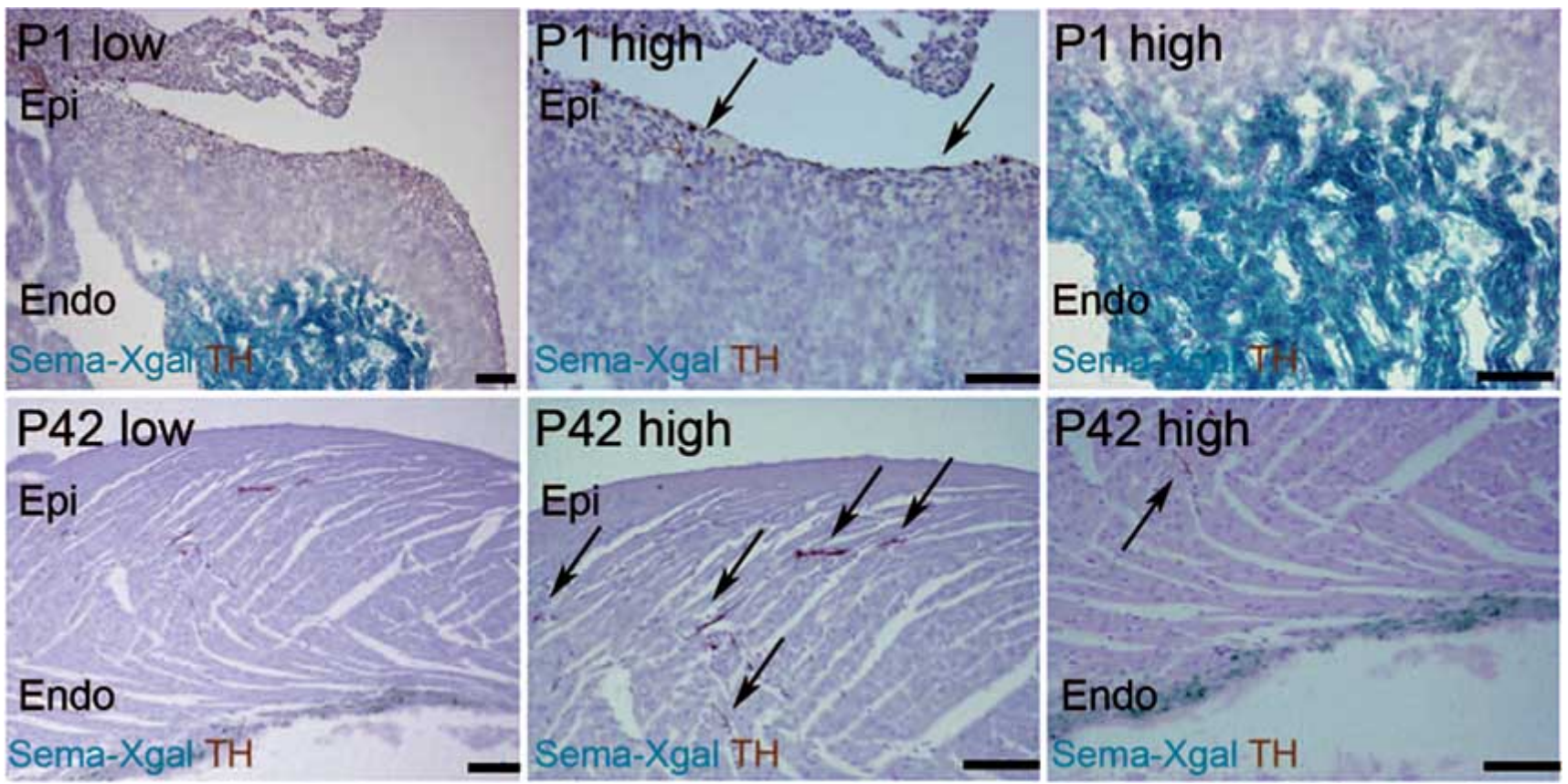

Fig. (3). Inverse expression pattern of Sema3a and sympathetic innervation in mouse hearts.

Double staining with TH (brown) and X-gal (blue) in P1 and P42 Sema3a ${ }^{\text {lacZ/+ }}$ hearts. Sympathetic nerves are restricted to the subepicardium at P1, but extend into the myocardium, coincident with downregulation of Sema3a at P42. Scale bar, $100 \mu \mathrm{m}$.

\section{SEMA3A DEFICIENT MICE SHOW SINUS ARREST AND SUDDEN DEATH}

To investigate whether Sema3a is critical for cardiac sympathetic nerve development, we analyzed Sema3a-deficient mice $\left(\mathrm{Sema3a}^{-1-}\right)[55,61,62]$. The WT hearts showed a clear epicardial-to-endocardial gradient of sympathetic innervation. By comparison, the sympathetic nerve density was reduced in the subepicardium and enhanced in the subendocardium of $\mathrm{Sema3a}^{-/-}$mice, resulting in disruption of the innervation gradient in Sema3a ${ }^{-/-}$ventricles. The Sema $3 a^{-/}$mice also exhibited malformation of the stellate ganglia that extend sympathetic nerves to the heart.

Strikingly, we also found that most of the Sema3a $a^{-/-}$mice died within the first postnatal week, with only $20 \%$ surviving until weaning [55, 61, 62]. To identify the cause of death and the effects of abnormal sympathetic neural distribution in Sema $3 a^{-/}$hearts, we performed telemetric electrocardiography and heart-rate variability analysis [63, 64]. In addition to multiple premature ventricular contractions, Sema3a ${ }^{1}$ mice developed sinus bradycardia and abrupt sinus arrest due to sympathetic neural dysfunction (Fig. 4).

\section{SEMA3A-OVEREXPRESSION \\ CAUSES VENTRICULAR TACHYARRHYTHMIAS DUE TO INNERVATION PATTERNING DEFECTS}

We generated transgenic mice that overexpressed Sema3a specifically in the heart (SemaTG) to determine if the phenotype observed in Sema3a ${ }^{-/-}$hearts is a secondary effect of stellate ganglia malformation [65]. This possibility was discounted as SemaTG mice showed reduced sympathetic innervation and attenuation of the epicardial-toendocardial innervation gradient.
The SemaTG mice died suddenly without symptoms at 10 months of age. Sustained ventricular tachyarrhythmia was induced in SemaTG mice, but not in WT mice, after epinephrine administration, and programmed electrical stimulation revealed that SemaTG mice were highly susceptible to ventricular tachyarrhythmia (Fig. 4 and 5) [66, $67]$. The $\beta 1$-adrenergic receptor density was upregulated and the cAMP response after catecholamine injection was exaggerated in SemaTG ventricles. Action potential duration was significantly prolonged in hypoinnervated SemaTG ventricles, presumably via ion channel modulation. These results suggest that the higher susceptibility of SemaTG mice to ventricular arrhythmia is due to catecholamine supersensitivity and prolongation of action potential duration, both of which can augment triggered activity in cardiomyocytes [68-72]. Thus, Sema3a-mediated sympathetic innervation patterning is critical for the maintenance of arrhythmia-free hearts.

\section{CONCLUSIONS}

Cardiac nerves are highly plastic, and the balance between NGF and Sema3a synthesized in the heart determines cardiac innervation patterning (Fig. 5). ET-1 upregulates NGF expression in cardiomyocytes, modulates nerve sprouting and plays critical roles in sympathetic nerve development [27, 54]. NGF is also important for sensory innervation, and NGF downregulation may result in silent myocardial ischemia and SCD in diabetic patients [20]. On the other hand, Sema3a inhibits neural growth and establishes appropriate innervation patterning in the heart. Both Sema3a deficiency and overexpression reveal lethal arrhythmias and sudden death due to disruption of sympathetic innervation patterning, suggesting fine tuning of Sema3a is critical for cardiac function. Thus, identification of the 


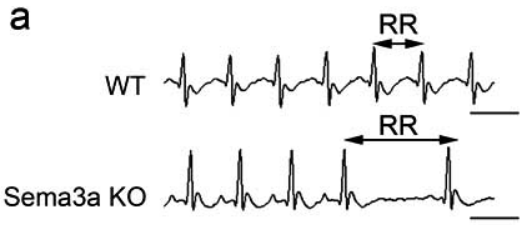

b
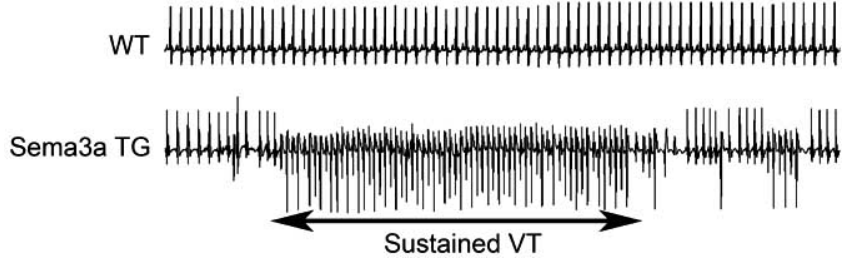

Fig. (4). Various arrhythmias occurred in Sema3a gene-modified mice.

(a) ECG in WT and Sema3 $a^{-/-}$mice. Note the abrupt sinus-slowing in Sema3 $a^{-/-}$mice. (b) Epinephrine administration revealed sustained VT only in SemaTG mice.

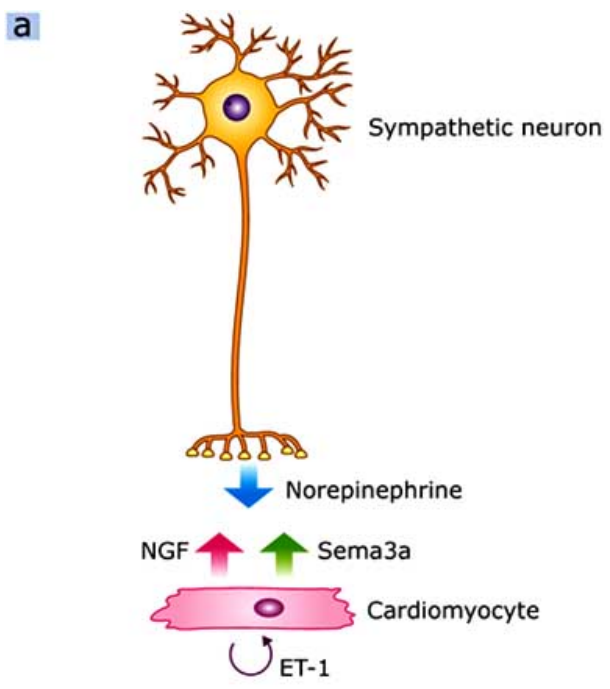

b

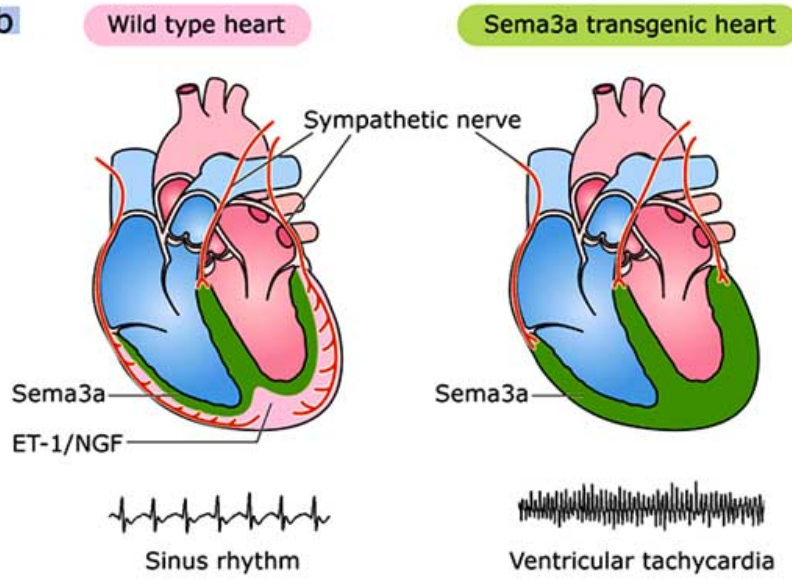

Fig. (5). Cardiac innervation patterning and lethal arrhythmias.

The crosstalk between cardiomyocytes and sympathetic neurons. Neurons synthesize norepinephrine, and cardiomyocytes secret NGF and Sema3a to control cardiac performance. (b) Appropriate Sema3a-mediated sympathetic innervation patterning is critical for the maintenance of an arrhythmia-free heart. SemaTG mice are highly susceptible to ventricular tachyarrhythmias. molecular mechanisms regulating cardiac innervation would improve our general understanding of cardiac performance and disease.

\section{ACKNOWLEDGMENTS}

This study was supported in part by research grants from the Ministry of Education, Culture, Sports, Science and Technology, Japan, and the Program for Promotion of Fundamental Studies in Health Sciences of the National Institute of Biomedical Innovation.

\section{REFERENCES}

[1] Cao JM, Chen LS, KenKnight BH, et al. Nerve sprouting and sudden cardiac death. Circ Res 2000; 86: 816-21.

[2] Kaye DM, Vaddadi G, Gruskin SL, Du XJ, Esler MD. Reduced myocardial nerve growth factor expression in human and experimental heart failure. Circ Res 2000; 86: E80-4.

[3] Cao JM, Fishbein MC, Han JB, et al. Relationship between regional cardiac hyperinnervation and ventricular arrhythmia. Circulation 2000; 101: 1960-9.

[4] Chen LS, Zhou S, Fishbein MC, Chen PS. New perspectives on the role of autonomic nervous system in the genesis of arrhythmias. J Cardiovasc Electrophysiol 2007; 18: 123-7.

[5] Chen PS, Chen LS, Cao JM, Sharifi B, Karagueuzian HS, Fishbein MC. Sympathetic nerve sprouting, electrical remodeling and the mechanisms of sudden cardiac death. Cardiovasc Res 2001; 50 409-16.

[6] Dae MW, Lee RJ, Ursell PC, Chin MC, Stillson CA, Moise NS. Heterogeneous sympathetic innervation in German shepherd dogs with inherited ventricular arrhythmia and sudden cardiac death Circulation 1997; 96: 1337-42.

[7] Qu J, Robinson RB. Cardiac ion channel expression and regulation: the role of innervation. J Mol Cell Cardiol 2004; 37: 439-48.

[8] Hjalmarson A. Effects of beta blockade on sudden cardiac death during acute myocardial infarction and the postinfarction period. Am J Cardiol 1997; 80: 35J-9J.

[9] Poole-Wilson PA, Swedberg K, Cleland JG, et al. Comparison of carvedilol and metoprolol on clinical outcomes in patients with chronic heart failure in the Carvedilol Or Metoprolol European Trial (COMET): randomised controlled trial. Lancet 2003; 362: 7 13

[10] Faerman I, Faccio E, Milei J, et al. Autonomic neuropathy and painless myocardial infarction in diabetic patients. Histologic evidence of their relationship. Diabetes 1977; 26: 1147-58.

[11] Crowley C, Spencer SD, Nishimura MC, et al. Mice lacking nerve growth factor display perinatal loss of sensory and sympathetic 
neurons yet develop basal forebrain cholinergic neurons. Cell 1994; 76: 1001-11.

[12] Ito M, Zipes DP. Efferent sympathetic and vagal innervation of the canine right ventricle. Circulation 1994; 90: 1459-68.

[13] Crick SJ, Sheppard MN, Ho SY, Anderson RH. Localisation and quantitation of autonomic innervation in the porcine heart I: conduction system. J Anat 1999; 195: 341-57.

[14] Crick SJ, Wharton J, Sheppard MN, et al. Innervation of the human cardiac conduction system. A quantitative immunohistochemical and histochemical study. Circulation 1994; 89: 1697-708.

[15] Chow LT, Chow SS, Anderson RH, Gosling JA. Innervation of the human cardiac conduction system at birth. Br Heart J 1993; 69: 430-5.

[16] Hansson M, Kjorell U, Forsgren S. Increased immunoexpression of atrial natriuretic peptide in the heart conduction system of the rat after cardiac sympathectomy. J Mol Cell Cardiol 1998; 30: 204757

[17] Randall WC, Szentivanyi M, Pace JB, Wechsler JS, Kaye MP. Patterns of sympathetic nerve projections onto the canine heart. Circ Res 1968; 22: 315-23.

[18] Schultz HD, Ustinova EE. Capsaicin receptors mediate free radicalinduced activation of cardiac afferent endings. Cardiovasc Res 1998; 38: 348-55

[19] Hua F, Harrison T, Qin C, et al. c-Fos expression in rat brain stem and spinal cord in response to activation of cardiac ischemiasensitive afferent neurons and electrostimulatory modulation. Am J Physiol Heart Circ Physiol 2004; 287: H2728-38.

[20] Ieda M, Kanazawa H, Ieda Y, et al. Nerve growth factor is critical for cardiac sensory innervation and rescues neuropathy in diabetic hearts. Circulation 2006; 114: 2351-63.

[21] Snider WD. Functions of the neurotrophins during nervous system development: what the knockouts are teaching us. Cell 1994; 77: 627-38.

[22] Lockhart ST, Turrigiano GG, Birren SJ. Nerve growth factor modulates synaptic transmission between sympathetic neurons and cardiac myocytes. J Neurosci 1997; 17: 9573-82.

[23] Brennan C, Rivas-Plata K, Landis SC. The p75 neurotrophin receptor influences NT-3 responsiveness of sympathetic neurons in vivo. Nat Neurosci 1999; 2: 699-705.

[24] Heumann R, Korsching S, Scott J, Thoenen H. Relationship between levels of nerve growth factor (NGF) and its messenger RNA in sympathetic ganglia and peripheral target tissues. EMBO J 1984; 3: 3183-9.

[25] Kanki H, Fukuda K, Okushi K, et al. Comparison of nerve growth factor mRNA expression in cardiac and skeletal muscle in streptozotocin-induced diabetic mice. Life Sci 1999; 65: 2305-13.

[26] Zhou S, Chen LS, Miyauchi Y, et al. Mechanisms of cardiac nerve sprouting after myocardial infarction in dogs. Circ Res 2004; 95: 76-83.

[27] Kimura K, Ieda M. Kanazawa $\mathrm{H}$, et al. Cardiac sympathetic rejuvenation: a link between nerve function and cardiac hypertrophy. Circ Res 2007; 100: 1755-64.

[28] Kuo DC, Oravitz JJ, DeGroat WC. Tracing of afferent and efferent pathways in the left inferior cardiac nerve of the cat using retrograde and transganglionic transport of horseradish peroxidase. Brain Res 1984; 321: 111-8.

[29] Zahner MR, Li DP, Chen SR, Pan HL. Cardiac vanilloid receptor 1 -expressing afferent nerves and their role in the cardiogenic sympathetic reflex in rats. J Physiol 2003; 551: 515-23.

[30] Bennett DL, Dmietrieva N, Priestley JV, Clary D, McMahon SB. trkA, CGRP and IB4 expression in retrogradely labelled cutaneous and visceral primary sensory neurones in the rat. Neurosci Lett 1996; 206: 33-6.

[31] Trupp M, Ryden M, Jornvall H, et al. Peripheral expression and biological activities of GDNF, a new neurotrophic factor for avian and mammalian peripheral neurons. J Cell Biol 1995; 130: 137-48.

[32] Kuruvilla R, Zweifel LS, Glebova NO, et al. A neurotrophin signaling cascade coordinates sympathetic neuron development through differential control of TrkA trafficking and retrograde signaling. Cell 2004; 118: 243-55.

[33] Wang L, Wang DH. TRPV1 gene knockout impairs postischemic recovery in isolated perfused heart in mice. Circulation 2005; 112: 3617-23.

[34] Pan HL, Chen SR. Sensing tissue ischemia: another new function for capsaicin receptors? Circulation 2004; 110: 1826-31.
[35] Park AM, Armin S, Azarbal A, Lai A, Chen PS, Fishbein MC. Distribution of cardiac nerves in patients with diabetes mellitus: an immunohistochemical postmortem study of human hearts. Cardiovasc Pathol 2002; 11: 326-31.

[36] Schratzberger P, Walter DH, Rittig K, et al. Reversal of experimental diabetic neuropathy by VEGF gene transfer. J Clin Invest 2001; 107: 1083-92.

[37] Fernyhough P, Diemel LT, Hardy J, Brewster WJ, Mohiuddi L, Tomlinson DR. Human recombinant nerve growth factor replaces deficient neurotrophic support in the diabetic rat. Eur J Neurosci 1995; 7: 1107-10.

[38] Christianson JA, Riekhof JT, Wright DE. Restorative effects of neurotrophin treatment on diabetes-induced cutaneous axon loss in mice. Exp Neurol 2003; 179: 188-99.

[39] Unger JW, Klitzsch T, Pera S, Reiter R. Nerve growth factor (NGF) and diabetic neuropathy in the rat: morphological investigations of the sural nerve, dorsal root ganglion, and spinal cord. Exp Neurol 1998; 153: 23-34.

[40] Bierhaus A, Haslbeck KM, Humpert PM, et al. Loss of pain perception in diabetes is dependent on a receptor of the immunoglobulin superfamily. J Clin Invest 2004; 114: 1741-51.

[41] Feldman EL, Russell JW, Sullivan KA, Golovoy D. New insights into the pathogenesis of diabetic neuropathy. Curr Opin Neurol 1999; 12: 553-63.

[42] Emanueli C, Salis MB, Pinna A, Graiani G, Manni L, Madeddu P. Nerve growth factor promotes angiogenesis and arteriogenesis in ischemic hindlimbs. Circulation 2002; 106: 2257-62.

[43] Hellweg R, Hartung HD. Endogenous levels of nerve growth factor (NGF) are altered in experimental diabetes mellitus: a possible role for NGF in the pathogenesis of diabetic neuropathy. J Neurosci Res 1990; 26: 258-67.

[44] Schmid H, Forman LA, Cao X, Sherman PS, Stevens MJ. Heterogeneous cardiac sympathetic denervation and decreased myocardial nerve growth factor in streptozotocin-induced diabetic rats: implications for cardiac sympathetic dysinnervation complicating diabetes. Diabetes 1999; 48: 603-8.

[45] Hellweg R, Raivich G, Hartung HD, Hock C, Kreutzberg GW. Axonal transport of endogenous nerve growth factor (NGF) and NGF receptor in experimental diabetic neuropathy. Exp Neurol 1994; 130: 24-30.

[46] Futamatsu H, Suzuki J, Mizuno S, et al. Hepatocyte growth factor ameliorates the progression of experimental autoimmune myocarditis: a potential role for induction of $\mathrm{T}$ helper 2 cytokines. Circ Res 2005; 96: 823-30.

[47] Sakata K, Kumagai H, Osaka M, et al. Potentiated sympathetic nervous and renin-angiotensin systems reduce nonlinear correlation between sympathetic activity and blood pressure in conscious spontaneously hypertensive rats. Circulation 2002; 106: 620-5.

[48] Apfel SC, Schwartz S, Adornato BT, et al. Efficacy and safety of recombinant human nerve growth factor in patients with diabetic polyneuropathy: A randomized controlled trial. rhNGF Clinical Investigator Group. JAMA 2000; 284: 2215-21.

[49] Goss JR, Goins WF, Lacomis D, Mata M, Glorioso JC, Fink DJ. Herpes simplex-mediated gene transfer of nerve growth factor protects against peripheral neuropathy in streptozotocin-induced diabetes in the mouse. Diabetes 2002; 51: 2227-32.

[50] Sasaki K, Chancellor MB, Goins WF, et al. Gene therapy using replication-defective herpes simplex virus vectors expressing nerve growth factor in a rat model of diabetic cystopathy. Diabetes 2004; 53: 2723-30.

[51] Zhan Y, Kim S, Izumi Y, et al. Role of JNK, p38, and ERK in platelet-derived growth factor-induced vascular proliferation, migration, and gene expression. Arterioscler Thromb Vasc Biol 2003; 23: 795-801.

[52] Francis N, Farinas I, Brennan C, et al. NT-3, like NGF, is required for survival of sympathetic neurons, but not their precursors. Dev Biol 1999; 210: 411-27.

[53] Hassankhani A, Steinhelper ME, Soonpaa MH, et al. Overexpression of NGF within the heart of transgenic mice causes hyperinnervation, cardiac enlargement, and hyperplasia of ectopic cells. Dev Biol 1995; 169: 309-21.

[54] Ieda M, Fukuda K, Hisaka Y, et al. Endothelin-1 regulates cardiac sympathetic innervation in the rodent heart by controlling nerve growth factor expression. J Clin Invest 2004; 113: 876-84. 
[55] Ieda M, Kanazawa H, Kimura K, et al. Sema3a maintains normal heart rhythm through sympathetic innervation patterning. Nat Med 2007; 13: 604-12.

[56] Puschel AW, Adams RH, Betz H. Murine semaphorin D/collapsin is a member of a diverse gene family and creates domains inhibitory for axonal extension. Neuron 1995; 14: 941-8.

[57] Tanelian DL, Barry MA, Johnston SA, Le T, Smith GM. Semaphorin III can repulse and inhibit adult sensory afferents in vivo. Nat Med 1997; 3: 1398-401.

[58] Kawasaki T, Bekku Y, Suto F, et al. Semaphorin III can repulse and inhibit adult sensory afferents in vivo. Development 2002; 129: 671-80.

[59] Tago H, Kimura H, Maeda T. Visualization of detailed acetylcholinesterase fiber and neuron staining in rat brain by a sensitive histochemical procedure. J Histochem Cytochem 1986; 34: 1431-8.

[60] Kupershmidt S, Yang T, Anderson ME, et al. Replacement by homologous recombination of the $\operatorname{minK}$ gene with lacZ reveals restriction of $\operatorname{minK}$ expression to the mouse cardiac conduction system. Circ Res 1999; 84: 146-52.

[61] Behar O, Golden JA, Mashimo H, Schoen FJ, Fishman MC. Semaphorin III is needed for normal patterning and growth of nerves, bones and heart. Nature 1996; 383: 525-8.

[62] Taniguchi M, Yuasa S, Fujisawa H, et al. Disruption of semaphorin III/D gene causes severe abnormality in peripheral nerve projection. Neuron 1997; 19: 519-30.

[63] Shusterman V, Usiene I, Harrigal C, et al. Strain-specific patterns of autonomic nervous system activity and heart failure susceptibility in mice. Am J Physiol Heart Circ Physiol 2002; 282: H2076-83.
[64] Saba S, London B, Ganz L. Autonomic blockade unmasks maturational differences in rate-dependent atrioventricular nodal conduction and facilitation in the mouse. $\mathrm{J}$ Cardiovasc Electrophysiol 2003; 14: 191-5.

[65] Gulick J, Subramaniam A, Neumann J, Robbins J. Isolation and characterization of the mouse cardiac myosin heavy chain genes. J Biol Chem 1991; 266: 9180-5.

[66] Wehrens XH, Lehnart SE, Reiken SR, et al. Protection from cardiac arrhythmia through ryanodine receptor-stabilizing protein calstabin2. Science 2004; 304: 292-6.

[67] Kannankeril PJ, Mitchell BM, Goonasekera SA, et al. Mice with the R176Q cardiac ryanodine receptor mutation exhibit catecholamine-induced ventricular tachycardia and cardiomyopathy. Proc Natl Acad Sci U S A 2006; 103: 12179-84.

[68] Kuo HC, Cheng CF, Clark RB, et al. A defect in the Kv channelinteracting protein 2 (KChIP2) gene leads to a complete loss of I(to) and confers susceptibility to ventricular tachycardia. Cell 2001; 107: 801-13.

[69] Opthof T, Misier AR, Coronel R, et al. Dispersion of refractoriness in canine ventricular myocardium. Effects of sympathetic stimulation. Circ Res 1991; 68: 1204-15.

[70] Priori SG, Corr PB. Mechanisms underlying early and delayed afterdepolarizations induced by catecholamines. Am J Physiol 1990; 258: H1796-805.

[71] Brunet S, Aimond F, Li H, et al. Heterogeneous expression of repolarizing, voltage-gated $\mathrm{K}+$ currents in adult mouse ventricles. $\mathrm{J}$ Physiol 2004; 559: 103-20.

[72] Costantini DL, Arruda EP, Agarwal P, et al. The homeodomain transcription factor Irx 5 establishes the mouse cardiac ventricular repolarization gradient. Cell 2005; 123: 347-58. 